\title{
The Effects of Anaerobiosis on Nitrogenase Synthesis and Heterocyst Development by Nostocacean Cyanobacteria
}

\author{
By R. RIPPKA AND R. Y. STANIER \\ Unité de Physiologie Microbienne, Département de Biochimie et Génétique Microbienne, \\ Institut Pasteur, 28 rue du Docteur Roux, 75724 Paris Cedex 15, France
}

(Received 29 September 1977)

Effective nitrogenase synthesis by nostocacean cyanobacteria (including one mutant strain unable to form heterocysts or fix nitrogen aerobically) was induced in the light in the absence of molecular oxygen. Anaerobiosis was maintained during induction by treating the organisms with dichloromethylurea which prevents photosynthetic oxygen production. Under these special conditions both synthesis and activity of nitrogenase were lightdependent, the required ATP being produced by cyclic photophosphorylation. Enzyme synthesis and activity were also dependent on the availability of an organic substrate that could serve both as a general source of carbon and as a source of reductant. The organic requirement could be fulfilled by the intracellular glycogen reserve or, in facultative heterotrophs, by a utilizable sugar (e.g. glucose). Nitrogenase synthesized anaerobically was highly susceptible to inactivation by molecular oxygen in vivo: exposure of a suspension of anaerobically induced filaments to $20 \%(\mathrm{v} / \mathrm{v}) \mathrm{O}_{2}$ for $1 \mathrm{~h}$ caused total and irreversible destruction of the enzyme. Anaerobic nitrogenase synthesis was not accompanied by the differentiation of mature heterocysts, the morphogenetic process being arrested at an early (proheterocyst) stage. After the gratuitous anaerobic synthesis of nitrogenase, introduction of either $\mathrm{N}_{2}$, nitrate or ammonia to the illuminated, anaerobic suspension resulted in a rapid accumulation of cyanophycin granules in both vegetative cells and proheterocysts. Cyanophycin was randomly deposited in vegetative cells, but localized at the cell poles of the proheterocysts. The bearing of these findings on the role played by the heterocyst in nitrogen fixation is discussed.

\section{INTRODUCTION}

Among filamentous cyanobacteria, the ability to fix nitrogen aerobically is correlated with the ability to form a differentiated cell, the heterocyst (Fogg, 1949; Stewart, 1969). As first suggested by Stewart, Haystead \& Pearson (1969), the heterocyst has special properties that enable it to protect the enzyme nitrogenase from inactivation by molecular oxygen; and much indirect evidence (reviewed by Stanier \& Cohen-Bazire, 1977) indicates that under aerobic conditions the heterocysts are the specific sites of nitrogen fixation in the filament.

Nitrogenase synthesis is repressed in all nitrogen-fixing organisms in the presence of a combined nitrogen source (Brill, 1975). In the special case of heterocystous cyanobacteria, heterocyst differentiation is also largely, and often totally, repressed under these conditions (Fogg, 1949). Removal of the nitrogen source causes a small fraction (5 to 10\%) of the vegetative cells that compose the filaments to differentiate into heterocysts; and if the process takes place under aerobic conditions, the formation of mature heterocysts is closely correlated with the development of nitrogenase activity in the filament population (Neilson, Rippka \& Kunisawa, 1971; Kulasooriya, Lang \& Fay, 1972).

The conversion of a vegetative cell into a mature heterocyst is a complex morphogenetic process (Wilcox, Mitchison \& Smith, 1973). Its first manifestation is the synthesis of 
Table 1. Some properties of the nostocacean cyanobacteria used for experiments

$\begin{array}{cclccccc}\begin{array}{c}\text { Paris } \\ \text { collection } \\ \text { no. }\end{array} & \text { no. } & \text { Other designations } & \begin{array}{c}\text { Aerobic } \\ \text { nitrogen } \\ \text { fixation }\end{array} & \begin{array}{c}\text { Hetero- } \\ \text { cysts } \\ \text { formed }\end{array} & \begin{array}{c}\text { Facultative } \\ \text { heterotrophy }\end{array} & \begin{array}{c}\text { Host to } \\ \text { phage N-1 }\end{array} & \begin{array}{c}\text { Nature of } \\ \text { growth in } \\ \text { liquid media }\end{array} \\ 6411 & 27898 & \text { UTEX1597* } & + & + & - & + & \text { Dispersed } \\ 6310 & 27896 & \begin{array}{l}\text { Anabaena spiroides } \\ \text { UTEX1552 }\end{array} & + & + & + & - & \text { Clumped } \\ 7118 & 27892 & \begin{array}{l}\text { Anabaena variabilis } \\ 7\end{array} & - & - & - & + & \text { Dispersed }\end{array}$

* Culture Collection of Algae at the University of Texas, formerly Indiana University Culture Collection.

additional cell envelopes, deposited around the vegetative cell wall. This is followed by a reorganization of the polar regions of the proheterocyst in contact with adjacent vegetative cells; they become narrow and elongated. The base of this specialized polar region is characteristically occupied, in the mature heterocyst, by a refractile and electron-dense granule, shown by Fogg (1951) to be rich in arginine. This suggests that it is composed of the cyanobacterial reserve material cyanophycin, a copolymer of arginine and aspartic acid (Simon, 1971). During early stages of differentiation, the developing heterocyst retains the ability to revert to a vegetative cell. The mature heterocyst can no longer dedifferentiate (Wilcox et al., 1973).

Rippka \& Waterbury (1977) have recently described a technique for the induction of nitrogenase synthesis in cyanobacteria under strictly anaerobic conditions; they used this technique to screen non-heterocystous members of the group for the potential capacity to fix nitrogen. The same technique has permitted us to study cellular differentiation and nitrogenase synthesis in heterocystous cyanobacteria in the absence of oxygen; the results are reported here.

\section{METHODS}

Biological material. Properties of the three strains of cyanobacteria used in this work are listed in Table 1. Strains 6310 and 6411 are typical nostocacean cyanobacteria. Strain 7118 , although identified by E. G. Pringsheim as Anabaena variabilis in 1950, shortly after its isolation (Kratz \& Myers, 1955), cannot fix nitrogen aerobically or form heterocysts. These properties appear to have been lost early in its culture history, since Kratz \& Myers (1955) reported that this strain was not a nitrogen-fixer. Hence the taxonomic status of strain 7118, which has been widely used for physiological and biochemical studies (Carr, 1973; Smith, 1973), has been open to question for many years. Two observations confirm that it is indeed a nostocacean cyanobacterium. Firstly, it is a host for cyanophage N-1, which attacks only cyanobacteria of this group (Adolph \& Haselkorn, 1971; Rippka \& Deruelles, unpublished observations). Secondly, we have been able to select rare revertants that have regained the ability to form heterocysts and to fix nitrogen aerobically; these arose after many weeks when strain 7118 was heavily inoculated on plates of medium BG-11 (Stanier et al., 1971) with combined nitrogen omitted, and incubated aerobically in the light.

Strain 6310, a facultative heterotroph (Kenyon, Rippka \& Stanier, 1972), was grown in the dark, in unshaken flasks of medium BG-11 (Stanier et al., 1971) supplemented with $0.5 \%(\mathrm{w} / \mathrm{v})$ glucose. Since this strain develops as clumps of filaments in liquid cultures, suspensions were homogenized at the time of harvesting by repeated passage through a hypodermic syringe. Strains 6411 and 7118 , both obligate autotrophs, were grown photosynthetically in medium BG-11, at an incident light intensity of 500 to 1000 lux, provided by Osram L-Interna fluorescent lamps. All cultures were grown at 25 to $30^{\circ} \mathrm{C}$, and were harvested during active growth by centrifuging aseptically. At the time of harvesting the absence of nitrogenase activity and of heterocysts was established.

Anaerobic induction experiments. The anaerobic induction of nitrogenase synthesis was performed essentially as described by Rippka \& Waterbury (1977). After harvesting from the growth medium, strains 6411 and 7118 , both obligate autotrophs, were subjected to preliminary nitrogen starvation in the presence of $\mathrm{CO}_{2}$ and in the light, in order to augment the cellular glycogen reserve (Allen \& Smith, 1969) upon which both the synthesis and activity of nitrogenase are dependent (Rippka \& Waterbury, 1977). In order to avoid the initiation of heterocyst differentiation in strain 6411, pretreatment was limited to a maximum of $10 \mathrm{~h}$. In experiments with the facultatively heterotrophic strain 6310 , filament suspensions were subjected to 
anaerobic induction without this pretreatment, the induction medium being supplemented with $0.5 \%(\mathrm{w} / \mathrm{v})$ glucose to provide a source of carbon and reducing power.

At the onset of anaerobic induction, the filament suspension was treated with $10^{-5} \mathrm{M}$-dichlorodimethylurea (DCMU), and placed under an atmosphere of argon containing an overpressure of $10 \%(\mathrm{v} / \mathrm{v})$ acetylene. The vessel was incubated at 25 to $30^{\circ} \mathrm{C}$ on a rotary shaker, under continuous illumination at an intensity of 2000 lux from an Osram L-Interna lamp.

Determination of nitrogenase synthesis. The inclusion of acetylene, a substrate of nitrogenase (Dilworth, 1966), in the gas phase of the vessel used for anaerobic induction permits determination of the course of nitrogenase synthesis by periodic removal of gas samples and measurement of their ethylene content (Rippka \& Waterbury, 1977). The increment in the ethylene content of the system between two successive gas samplings is a measure of the total nitrogenase activity over that time interval, and permits the calculation of an average specific activity for that interval. Specific activities are expressed as nmol ethylene produced $\mathrm{min}^{-1}$ ( $m g$ protein $)^{-1}$, based on the protein content of the filament suspension at the end of the induction period. Since the induction system contained neither $\mathrm{N}_{2}$ nor a combined nitrogen source, the protein content of the organisms remained constant, or diminished slightly, over the course of the induction.

Techniques of microscopy. Examination of living filaments by light microscopy was conducted on preparations mounted in water on agar-coated slides (Kenyon et al., 1972); micrographs were taken with Zeiss Neofluar objectives, using phase contrast illumination. A specific staining method, employing the Sakaguchi reaction (Fogg, 1951; Baker, 1947), was used to identify cyanophycin granules. The techniques for the preparation of specimens and their examination by electron microscopy are described elsewhere (Rippka, Waterbury \& Cohen-Bazire, 1974).

Chemicals. All chemicals were purchased from commercial sources and were of the highest purity obtainable. Gases were purchased from Air Liquide (Paris, France) and were of the following grades: argon, N50; nitrogen, N50; acetylene, N25; carbon dioxide, N45; oxygen, N45.

Analytical methods. Glycogen was extracted, hydrolysed and assayed by the glucostat method as described by Stanier et al. (1959). Protein was determined by the method of Lowry et al. (1951) after pretreatment of the cell samples as described by Neilson et al. (1971). Cyanophycin was extracted and determined quantitatively as described by Simon (1973), except that acid extraction of the isolated polypeptide was performed at $70^{\circ} \mathrm{C}$.

\section{RESULTS}

\section{Factors affecting the synthesis and activity of nitrogenase during anaerobic induction}

The anaerobic synthesis of nitrogenase by cyanobacteria when photosystem II activity was inhibited by DCMU was strictly light-dependent, since cyclic photophosphorylation was the only means by which the necessary ATP could be generated (Fig. 1). It was also dependent on the availability of an organic compound that could serve as a carbon source for amino acid synthesis. For an autotrophic strain, the carbon source could be provided by the intracellular glycogen reserve, and the extent of nitrogenase synthesis was a function of the size of the glycogen reserve at the start of induction (Table 2). For a facultatively heterotrophic strain, this requirement could be met by an exogenously supplied carbohydrate. The effect of glucose on anaerobic nitrogenase synthesis by the heterotrophic strain 6310 is shown in Fig. 2. In a suspension initially furnished with glucose, nitrogenase was detectable about $20 \mathrm{~h}$ after the onset of induction and the specific activity thereafter increased at a steady rate for over $10 \mathrm{~h}$. In a suspension not furnished with glucose, limited anaerobic nitrogenase synthesis occurred at the expense of glycogen, but the increase in specific activity was arrested at a low level a few hours after nitrogenase first became detectable. When glucose was added to the filament suspension at this time (arrow in Fig. 2), the specific activity did not immediately increase; the low level of activity observed following induction in the absence of glucose was therefore not caused by a limited supply of reductant (necessary for enzyme activity), but was a measure of the nitrogenase content of the cells. The addition of glucose was eventually followed by a resumption of nitrogenase synthesis; this secondary increase in activity was prevented by chloramphenicol (Fig. 2).

After the onset of anaerobic nitrogenase synthesis, the increase of specific activity was arrested by adding ammonia $(7.5 \mathrm{~mm})$ or nitrate $(15 \mathrm{~mm})$ to the filament suspension; the level of activity thereafter remained constant for many hours (Table 3 ). 


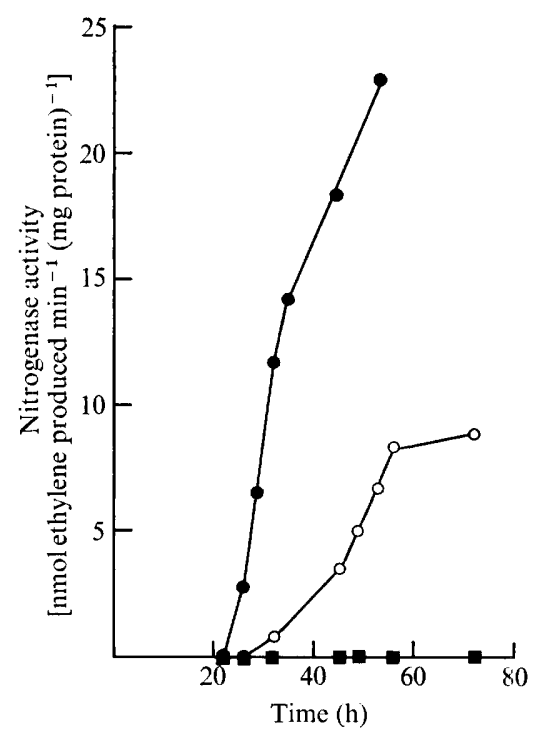

Fig. 1

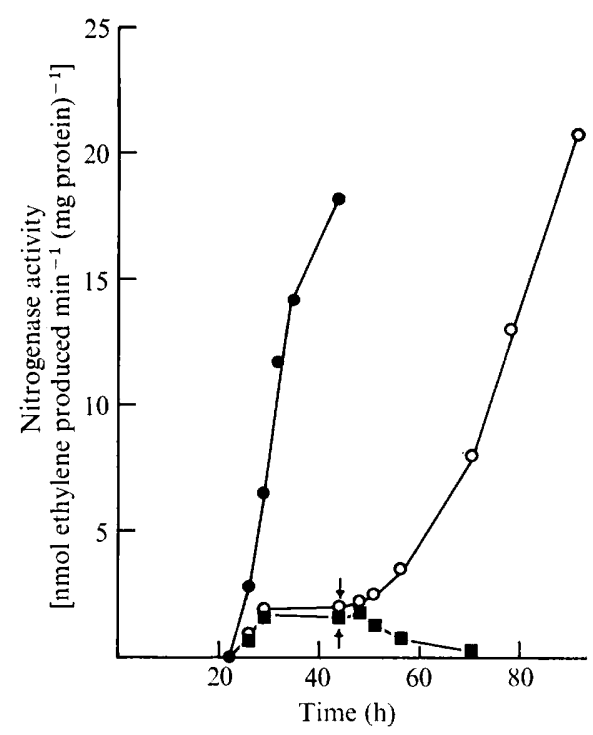

Fig. 2

Fig. 1. The influence of light intensity on the development of nitrogenase activity by suspensions of strain 6310 , anaerobically induced in the presence of $10^{-5} \mathrm{M}-\mathrm{DCMU}$ and $0.5 \%(\mathrm{w} / \mathrm{v})$ glucose under an atmosphere of argon/acetylene. Incident light intensity: 0, 2000 lux; 0,500 lux; $\square$, dark control.

Fig. 2. The influence of glucose on the development of nitrogenase activity by suspensions of strain 6310 , anaerobically induced in the light in the presence of $10^{-5} \mathrm{M}$-DCMU under an atmosphere of argon/acetylene. $0,0.5 \%(\mathrm{w} / \mathrm{v})$ glucose added at zero time; $0,0.5 \%(\mathrm{w} / \mathrm{v})$ glucose added (arrow) $44 \mathrm{~h}$ after initiation of induction; $\mathbf{0}, 0.5 \%(\mathrm{w} / \mathrm{v})$ glucose and $50 \mu \mathrm{g}$ chloramphenicol ml $\mathrm{m}^{-1}$ added (arrow) $44 \mathrm{~h}$ after initiation of induction. Incident light intensity: 2000 lux.

Table 2. Effect of the initial cellular glycogen content on the extent of the subsequent anaerobic synthesis of nitrogenase by strain 6411

\begin{tabular}{|c|c|c|}
\hline $\begin{array}{l}\text { Duration of preliminary } \\
\text { nitrogen starvation in } \\
\text { the light and in the } \\
\text { presence of } \mathrm{CO}_{2}(\mathrm{~h})\end{array}$ & 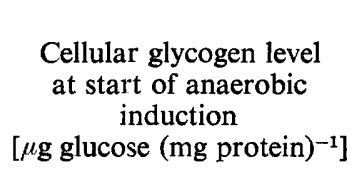 & $\begin{array}{l}\text { Maximum specific activity } \\
\text { of nitrogenase following } \\
\text { anaerobic induction } \\
\text { [nmol ethylene produced } \text { min }^{-1} \\
(\text { mg protein })^{-1} \text { ] }\end{array}$ \\
\hline 2 & 23 & 0.07 \\
\hline 6 & 33 & $1 \cdot 79$ \\
\hline 10 & 46 & $3 \cdot 93$ \\
\hline
\end{tabular}

\section{Effect of oxygen on the nitrogenase activity of anaerobically induced filaments}

After a high level of nitrogenase activity had developed anaerobically in a suspension of strain 6310 , an immediate cessation of acetylene reduction occurred if oxygen $[2 \%(\mathrm{v} / \mathrm{v})$ or greater] was introduced into the gas phase. This inhibitory effect of oxygen could in principle reflect reversible inhibition of enzyme activity (for example, by competition with acetylene for reductant) or irreversible denaturation of the enzyme. The former type of inhibition should be relieved by a reimposition of anaerobiosis, and the reappearance of activity should be unaffected by the addition to the system of chloramphenicol or ammonia. After irreversible denaturation of nitrogenase, the reappearance of enzymic activity following reimposition of anaerobiosis must reflect de novo enzyme synthesis, and should therefore be prevented by chloramphenicol or ammonia. Two experiments designed to examine this question were conducted with strain 6310; the results are shown in Fig. 3. Exposure of the suspension to $20 \%(\mathrm{v} / \mathrm{v}) \mathrm{O}_{2}$ for $1 \mathrm{~h}$ resulted in total and irreversible denaturation of nitro- 
Table 3. Effect of adding a source of combined nitrogen during anaerobic induction on the subsequent course of nitrogenase synthesis by strain 6310

Specific activity of nitrogenase [nmol ethylene produced min $^{-1}(\mathrm{mg} \text { protein })^{-1}$ ]

Addition after $27 \mathrm{~h}$
of anaerobic induction
None
$7.5 \mathrm{~mm}-\left(\mathrm{NH}_{4}\right)_{2} \mathrm{SO}_{4}$
$15 \mathrm{~mm}-\mathrm{NaNO}_{3}$

$\begin{array}{ccc}\text { At time of } & & \\ \text { addition } & 39 \mathrm{~h} \text { later } & \text { Increment } \\ 0.9 & 4.8 & +3.9 \\ 0.9 & 0.8 & -0.1 \\ 1.3 & 1.8 & +0.5\end{array}$
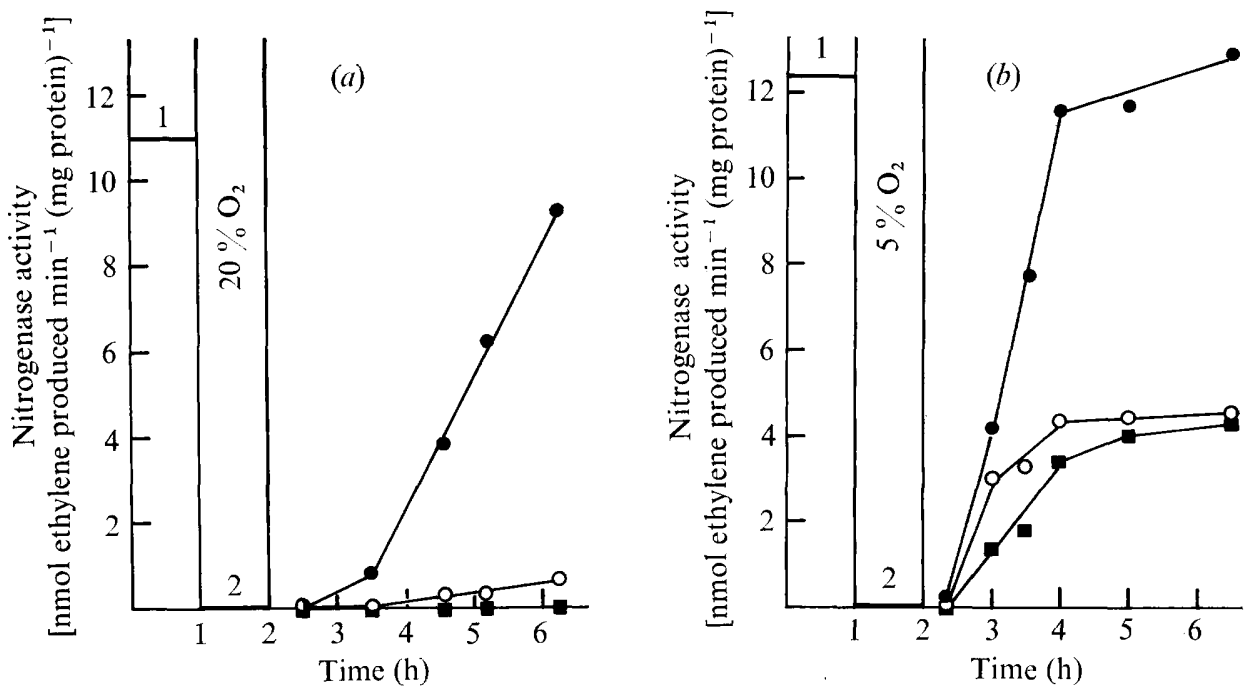

Fig. 3. The effect of transient exposure $(1 \mathrm{~h})$ to $20 \%(\mathrm{v} / \mathrm{v}) \mathrm{O}_{2}(a)$ or $5 \%(\mathrm{v} / \mathrm{v}) \mathrm{O}_{2}(b)$ on the nitrogenase activity of strain 6310 , after induction under strictly anaerobic conditions. The heavy horizontal bars represent specific activities (1) immediately before exposure to oxygen and (2) during exposure to oxygen. After exposure to oxygen each suspension was divided into three aliquots, which were reincubated anaerobically in the light with the following additions: $O, 7.5 \mathrm{~mm}-\left(\mathrm{NH}_{4}\right)_{2} \mathrm{SO}_{4}$; b, $50 \mu \mathrm{g}$ chloramphenicol $\mathrm{ml}^{-1} ; 0$, no addition. Incident light intensity: 2000 lux.

genase (Fig. $3 a$ ): no significant recovery of activity occurred under anaerobic conditions in the presence of chloramphenicol or ammonia. On the other hand, about $30 \%$ of the initial nitrogenase activity was recovered under anaerobic conditions in the presence of chloramphenicol or ammonia after exposure of the suspension to $5 \%(\mathrm{v} / \mathrm{v}) \mathrm{O}_{2}$ for $1 \mathrm{~h}$ (Fig. $3 \mathrm{~b}$ ). Since the introduction of $5 \%(\mathrm{v} / \mathrm{v}) \mathrm{O}_{2}$ immediately abolished acetylene reduction, it is evident that $\mathrm{O}_{2}$ has an immediate inhibitory effect on nitrogenase activity, as well as causing a slower irreversible denaturation of the enzyme in vivo.

\section{Influence of strict anaerobiosis on heterocyst development}

The experiments described above showed that the mechanisms for the protection of nitrogenase from inactivation by oxygen that normally operate in heterocystous cyanobacteria do not come into play after anaerobic induction of nitrogenase in strain 6310 . Anaerobically induced suspensions, examined at any time during the course of induction, were devoid of mature heterocysts (Fig. $4 a$ ), whereas these structures were present at a normal frequency in a control suspension after induction under otherwise identical conditions under an atmosphere containing $20 \%$ (v/v) $\mathrm{O}_{2}$ (Fig. 4b). As shown in Fig. 4(a), anaerobic 

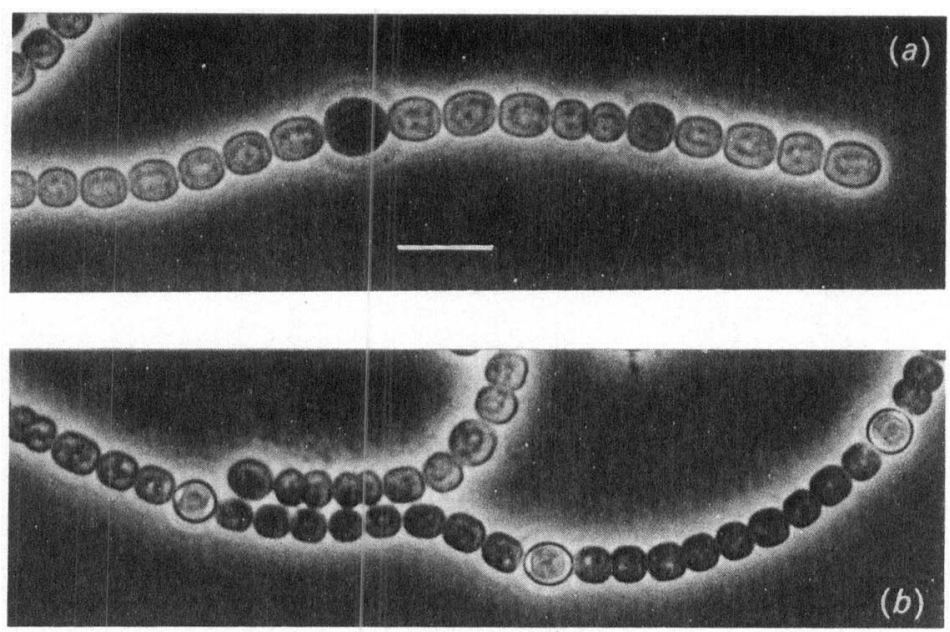

Fig. 4. Filaments of strain 6310 after induction in the presence of $10^{-5} \mathrm{M}-\mathrm{DCMU}$ and $0.5 \%(\mathrm{w} / \mathrm{v})$ glucose in the light $(a)$ anaerobically [argon/acetylene atmosphere] and $(b)$ aerobically [argon/ acetylene containing $20 \%(\mathrm{v} / \mathrm{v}) \mathrm{O}_{2}$ ]. Phase contrast; bar marker represents $10 \mu \mathrm{m}$.

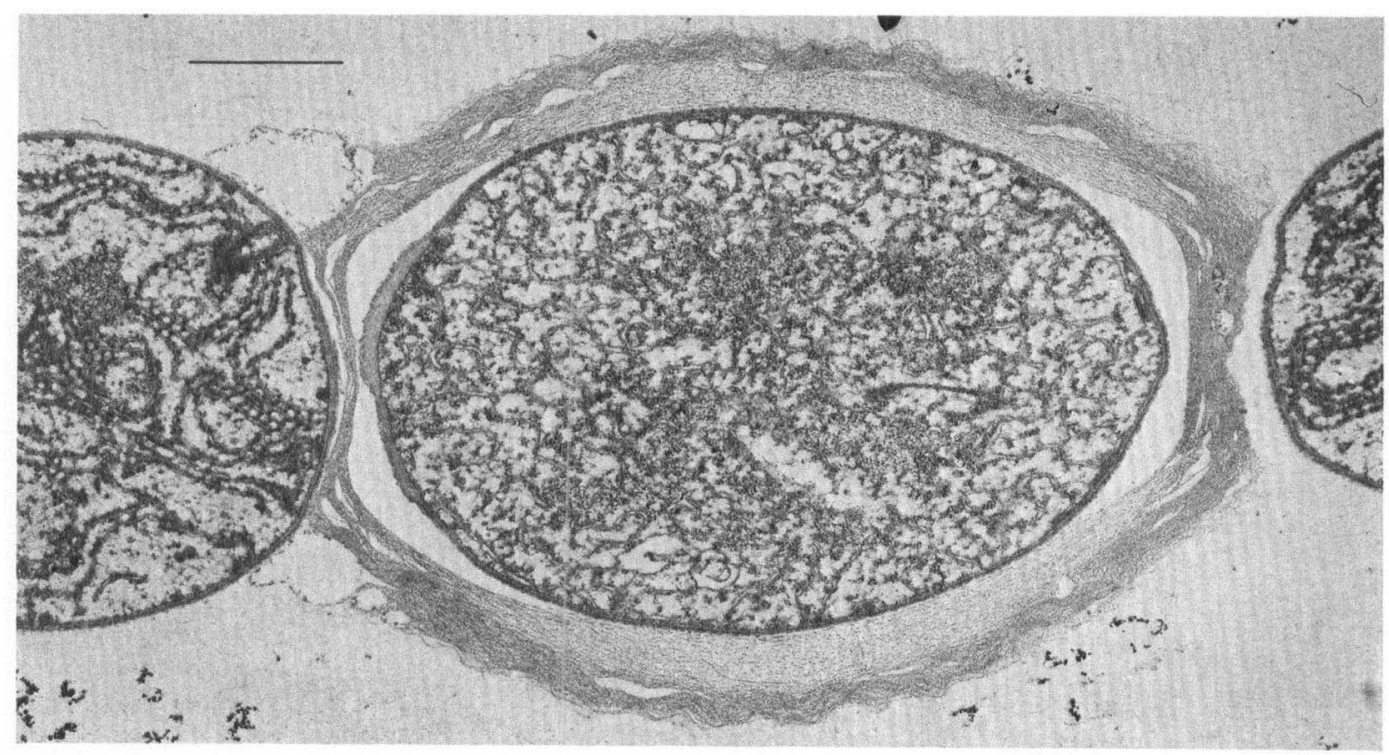

Fig. 5. Electron micrograph of a thin section of an anaerobically induced filament of strain 6310 , showing an intercalary proheterocyst together with parts of two adjoining vegetative cells. Note the difference in internal fine structure between the two kinds of cells, as well as the loose, fibrous envelope layer around the proheterocyst. Bar marker represents $1 \mu \mathrm{m}$.

induction leads to the formation in the filaments of cells that are interpretable as proheterocysts by virtue of their structure and spacing. As observed under phase contrast illumination, these cells are enclosed by a wide external envelope layer, absent from the adjacent vegetative cells, and are much less refractile than vegetative cells.

Electron microscopy of thin sections (Fig. 5) of these cells showed a fine structure corresponding to stage II proheterocysts as described by Wilcox et al. (1973): they were enclosed by only one of the three characteristic heterocyst envelopes, and the differentiation of the poles contiguous to adjacent vegetative cells had not been initiated. The extreme oxygen 


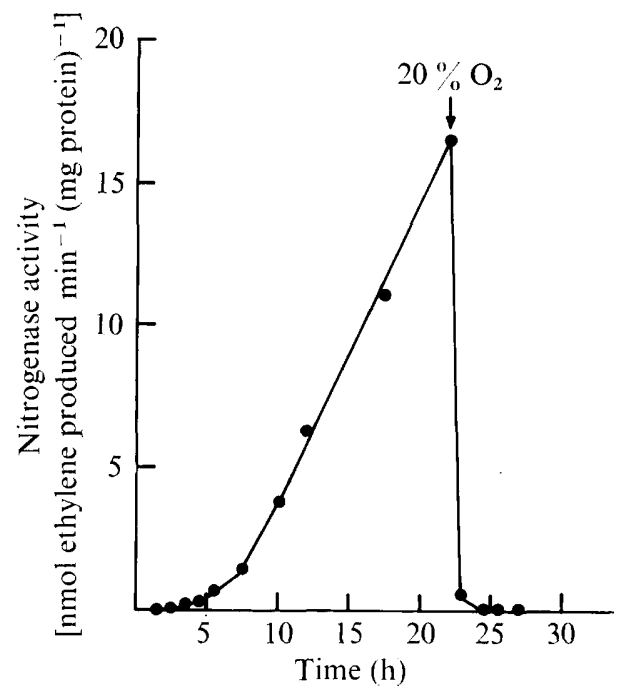

Fig. 6. The effect of exposure to $20 \%(\mathrm{v} / \mathrm{v}) \mathrm{O}_{2}$ (added at the time indicated by the arrow) on the nitrogenase activity of strain 7118 after induction under strictly anaerobic conditions at the expense of its intracellular glycogen reserve. Incident light intensity: 2000 lux.

sensitivity of nitrogenase induced anaerobically in this strain is therefore plausibly attributable to a premature arrest of heterocyst differentiation.

This behaviour was not peculiar to strain 6310. After anaerobic induction, the nitrogenase of strain 6411 was also oxygen-sensitive, and the filaments contained proheterocysts microscopically similar to those of strain 6310 .

The non-heterocyst-forming strain 7118 , although unable to fix nitrogen aerobically, synthesized high levels of nitrogenase when induced under anaerobic conditions; the enzyme was rapidly destroyed in vivo by exposure to molecular oxygen (Fig. 6). In this strain, cells interpretable as stage II proheterocysts were not visible in the filaments after anaerobic induction. Hence, if induction does lead to an onset of differentiation, the process must be arrested prior to stage II.

\section{Cyanophycin synthesis associated with anaerobic nitrogen fixation}

After anaerobic induction of nitrogenase under the conditions employed in this work, the filaments were nitrogen-starved and virtually devoid of cyanophycin, the characteristic nitrogenous reserve material of cyanobacteria. Cyanophycin depletion was revealed by the absence from both vegetative cells and proheterocysts of phase-bright granules giving a positive Sakaguchi reaction. The replacement of the argon/acetylene gas phase by $\mathrm{N}_{2}$ permitted the induced, nitrogen-starved filaments to initiate nitrogen fixation, and this was accompanied by a rapid synthesis and intracellular deposition of cyanophycin (Figs $7,8,9$ ). Marked granulation, first evident 4 to $8 \mathrm{~h}$ after the change of gas phase, occurred both in vegetative cells and in proheterocysts. The granules in proheterocysts were on the average somewhat larger than those in vegetative cells. They also differed in location, being situated exclusively at the two poles of the proheterocyst (thus occupying the same site as in the normal mature heterocyst). The cyanophycin granules in vegetative cells were numerous and randomly distributed (Fig. 7). The same characteristic pattern of cyanophycin accumulation occurred if the anaerobically induced filaments were furnished with a source of combined nitrogen [15 mM-NaNO${ }_{3}$ or $\left.7 \cdot 5 \mathrm{~mm}-\left(\mathrm{NH}_{4}\right)_{2} \mathrm{SO}_{4}\right]$ in place of $\mathrm{N}_{2}$.

Continued anaerobic incubation of induced filaments in the presence of $\mathrm{N}_{2}$ and in the light eventually resulted in the growth and division of some proheterocysts (Fig. 7). The 

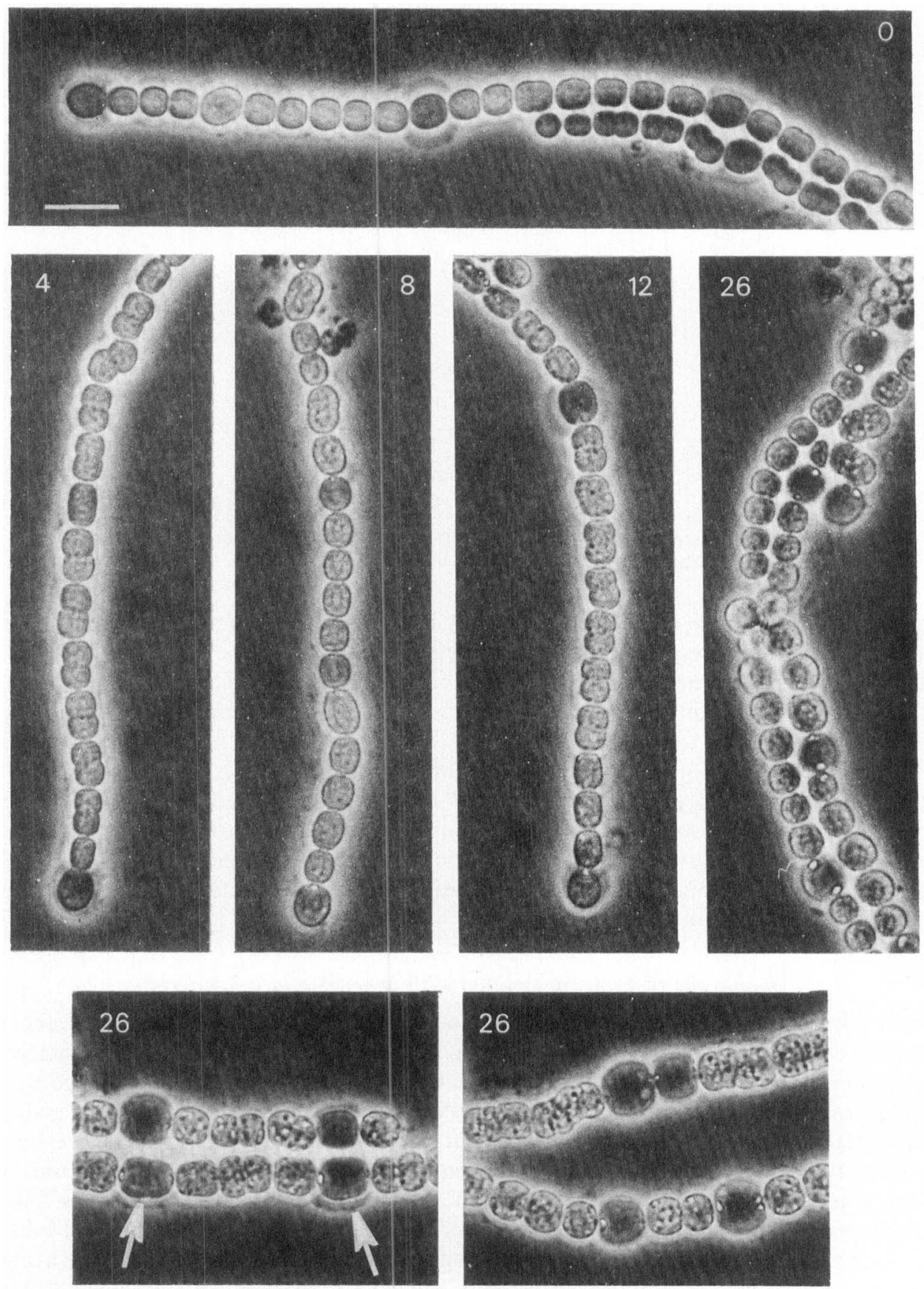

Fig. 7. Appearance of cyanophycin granules in strain 6310 exposed to $\mathrm{N}_{2}$ after anaerobic nitrogenase induction under an atmosphere of argon/acetylene. The number on each photomicrograph shows the time (hours) of exposure to $\mathrm{N}_{2}$. Arrows indicate dividing proheterocysts. Phase contrast; bar marker represents $10 \mu \mathrm{m}$. 


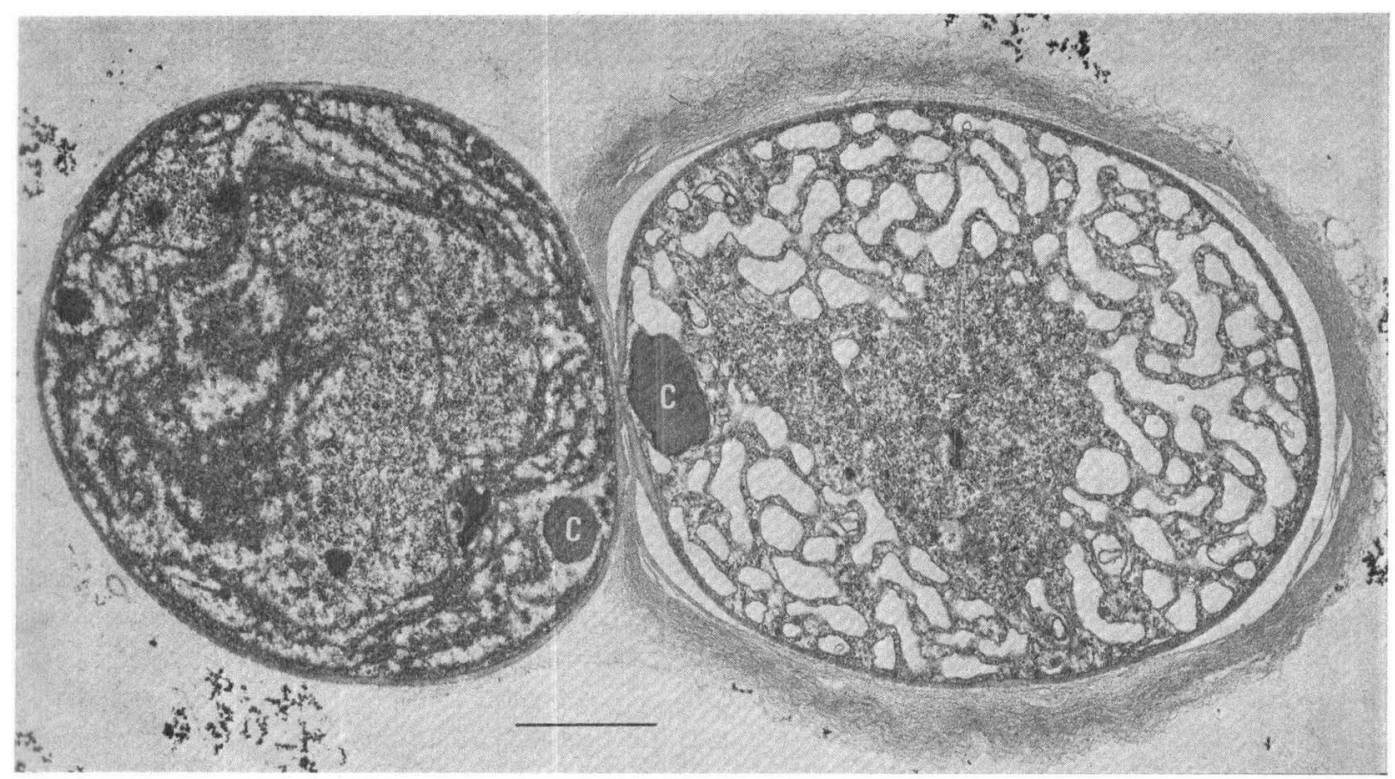

Fig. 8. Electron micrograph of a thin section of part of a filament of strain 6310 exposed for $10 \mathrm{~h}$ to an atmosphere of $\mathrm{N}_{2}$ after anaerobic nitrogenase induction under an atmosphere of argon/acetylene, showing a vegetative cell and proheterocyst, each containing cyanophycin granules (C). Bar marker represents $1 \mu \mathrm{m}$.

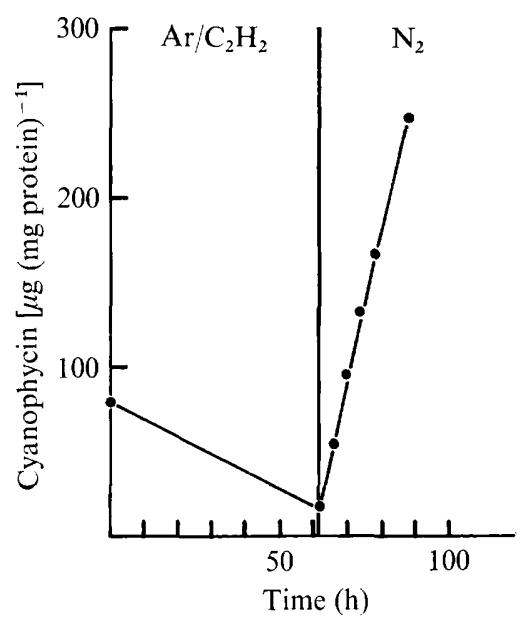

Fig. 9. Changes in the cyanophycin content of a filament suspension of strain 6310 over the course of an induction experiment. A high level of nitrogenase activity [15 $\left.\mathrm{nmol} \mathrm{m^{-1 }}(\mathrm{mg} \text { protein })^{-1}\right]$ was first induced under gratuitous conditions (argon/acetylene atmosphere); the gas phase was then replaced by $\mathrm{N}_{2}$, permitting nitrogen fixation to occur. Cyanophycin accumulated without detectable lag and at a high rate following the introduction of $\mathrm{N}_{2}$.

ability of the proheterocysts to divide is in accord with the observation of Wilcox et al. (1973) that reversion can occur at high frequency up to stage III of heterocyst differentiation.

\section{DISCUSSION}

In heterocystous cyanobacteria, withdrawal of a combined nitrogen source ('induction') under aerobic conditions has two consequences: differentiation of heterocysts, and development of oxygen-insensitive nitrogenase activity. Under the strictly anaerobic conditions of 
induction described here, heterocyst differentiation is arrested at an early stage. Furthermore, although nitrogenase is synthesized, its activity is totally and irreversibly destroyed by exposure of filaments to $20 \%(\mathrm{v} / \mathrm{v}) \mathrm{O}_{2}$ for $1 \mathrm{~h}$. This observation shows that proheterocysts (at least when formed under anaerobic conditions) are incapable of protecting nitrogenase from oxygen inactivation. The mechanism by which a mature heterocyst protects nitrogenase from oxygen inactivation is still unknown. The proheterocysts that develop anaerobically do not possess the multiple envelope layers characteristic of the mature heterocyst, and this might play a role in determining the oxygen sensitivity of the nitrogenase that they contain. However, it cannot be excluded a priori that the mechanism of protection also has enzymic components, themselves subject to induction by molecular oxygen, and therefore absent from proheterocysts which have differentiated anaerobically.

Although the importance of the heterocyst in the process of nitrogen fixation by heterocystous cyanobacteria is now generally acknowledged (for review, see Stanier \& CohenBazire, 1977), the question of whether it is the sole cellular site of nitrogenase activity in such cyanobacteria has remained open. The present study suggests that the answer to this question is dependent on the environmental conditions under which nitrogenase synthesis is induced. Our observations show that in the absence of molecular oxygen, the vegetative cells in the filament express the genetic information which encodes the synthesis of this enzyme. The most direct evidence in support of this conclusion is the observation that strain 7118, a spontaneous mutant which has lost the ability to form heterocysts and to fix nitrogen aerobically, can synthesize nitrogenase effectively in the absence of molecular oxygen.

In view of the extreme oxygen sensitivity in vivo of the nitrogenase synthesized by heterocystous cyanobacteria under anaerobic conditions of induction, it appears most unlikely that vegetative cells, even if they were derepressed for synthesis of the enzyme under aerobic conditions, could express nitrogenase function, since the enzyme would be inactivated as rapidly as it was synthesized. We conclude that under aerobic conditions the heterocyst is the sole cellular site of nitrogenase activity in the filament, although not necessarily the sole site of nitrogenase synthesis.

Since anaerobic induction of strains 6310 and 6411, which form normal heterocysts aerobically, leads to the development of proheterocysts, it might be argued that these cells are the specific sites of anaerobic nitrogenase synthesis. However, the pattern of cyanophycin deposition in the anaerobically induced filaments following the introduction of $\mathrm{N}_{2}$ strongly suggests that vegetative cells as well as proheterocysts are competent to fix nitrogen. Cyanophycin granules develop rapidly both in vegetative cells and in the polar regions of the proheterocysts, and there is no indication of a gradient of cyanophycin accumulation in vegetative cells, determined by their position relative to proheterocysts. Moreover, the patterns of cyanophycin accumulation in the filaments resulting from the addition of $\mathrm{N}_{2}$, ammonia or nitrate under anaerobic conditions in the light are indistinguishable. Were nitrogenase localized in proheterocysts, cyanophycin synthesis by vegetative cells after exposure to $\mathrm{N}_{2}$ could occur only following the transfer of fixed nitrogen from proheterocysts. It should therefore be delayed (relative to cyanophycin formation in proheterocysts) and show a gradient, cyanophycin granules appearing most rapidly in vegetative cells adjacent to proheterocysts. Neither of these predictions was met.

Van Gorkom \& Donze (1971) studied, by fluorescence measurement, the resynthesis of phycocyanin in nitrogen-starved filaments of Anabaena cylindrica after the introduction of $\mathrm{N}_{2}$ to the filament suspension. [Phycobiliprotein destruction is an invariable consequence of nitrogen depletion in cyanobacteria (Allen \& Smith, 1969).] Filaments subjected to prolonged nitrogen starvation under semi-anaerobic conditions $\left(\mathrm{H}_{2} / \mathrm{CO}_{2}\right.$ atmosphere $)$ in the light resynthesized phycocyanin more or less evenly in all vegetative cells when $\mathrm{N}_{2}$ was admitted anaerobically. However, when $\mathrm{N}_{2}$ was admitted aerobically, pronounced gradients of phycocyanin fluorescence were observed; fluorescence intensity was greatest in cells 
adjacent to heterocysts, and least in cells midway between two heterocysts. Van Gorkom \& Donze (1971) concluded (i) that under aerobic conditions, nitrogen fixation occurs exclusively in heterocysts, and (ii) that under anaerobic conditions, vegetative cells can also fix nitrogen. Their conclusions are, in this respect, identical with ours.

An unexpected outcome of the present study has been the demonstration that molecular oxygen markedly influences heterocyst development. In strains 6310 and 6411, nitrogen depletion under strictly anaerobic conditions initiates an apparently normal differentiation of some vegetative cells into proheterocysts, but development ceases following synthesis of the outer fibrous envelope layer. In strain 6310, proheterocysts can resume growth and division when furnished with a utilizable nitrogen source; this observation, combined with their ultrastructural properties, indicates that development is arrested at a stage corresponding approximately to stage II of normal heterocyst development, as defined by Wilcox et al. (1973). Thus, a relatively early event in the morphogenetic sequence is oxygendependent; and if this step is prevented, none of the later steps in heterocyst maturation (synthesis of additional envelope layers; development of the specialized polar junctional regions) can occur. However, the deposition of cyanophycin granules in these immature proheterocysts following exposure to $\mathrm{N}_{2}$ is identical with the pattern of deposition characteristic of a mature heterocyst. Cyanophycin granules are localized in the immediate neighbourhood of the two cell poles, and not (as in vegetative cells) scattered randomly throughout the cell. Furthermore, the same localized deposition of cyanophycin granules in the proheterocysts occurs if filaments are furnished with nitrate or ammonia in place of $\mathrm{N}_{2}$. This could reflect an early localization of the cyanophycin-synthesizing enzymes near the cell poles during proheterocyst development.

We are grateful to Dr J. B. Waterbury, Mme J. Deruelles and Mlle T. Coursin for their valuable aid, and to Professor R. Haselkorn for many helpful discussions. This work was supported by the Centre National de la Recherche Scientifique (E.R.A. 398).

\section{REFERENCES}

Adolph, K. W. \& HASELKoRn, R. (1971). Isolation and characterisation of a virus infecting the bluegreen alga Nostoc muscorum. Virology 46, 200208.

Allen, M. M. \& SMith, A. J. (1969). Nitrogen chlorosis in blue-green algae. Archiv für Mikrobiologie 69, 114-120.

BAKER, J. R. (1947). The histochemical recognition of certain guanidine derivatives. Quarterly Journal of Microscopical Science 88, 115-121.

BrILL, W. J. (1975): Regulation and genetics of bacterial nitrogen fixation. Annual Review of Microbiology 29, 109-129.

CARR, N. G. (1973). Metabolic control and autotrophic physiology. In The Biology of Blue-Green Algae, pp. 39-65. Edited by N. G. Carr and B. A. Whitton. Oxford: Blackwell Scientific Publications.

DilworTh, M. J. (1966). Acetylene reduction by nitrogen fixing preparations from Clostridium pasteurianum. Biochimica et biophysica acta 127, 285-294.

FoGG, G. E. (1949). Growth and heterocyst production in Anabaena cylindrica Lemm. II. In relation to carbon and nitrogen metabolism. Annals of Botany 13, 241-259.

FoGG, G. E. (1951). Growth and heterocyst production in Anabaena cylindrica Lemm. III. The cyto- logy of heterocysts. Annals of Botany 15, 2335.

KenYon, C. N., RipPKa, R. \& Stanier, R. Y. (1972). Fatty acid composition and physiological properties of some filamentous blue-green algae. Archiv für Mikrobiologie 83, 216-236.

Kratz, W. A. \& Myers, J. (1955). Nutrition and growth of several blue-green algae. American Journal of Botany 42, 282-287.

Kulasooriya, S. A., LANG, N. J. \& FAY, P. (1972). The heterocysts of blue-green algae. III. Differentiation and nitrogenase activity. Proceedings of the Royal Society B 181, 199-209.

Lowry, O. H., Rosebrough, N. J., Farr, A. L. \& RANDALL, R. J. (1951). Protein measurement with the Folin phenol reagent. Journal of Biological Chemistry 193, 265-275.

Neilson, A., Rippka, R. \& Kunisawa, R. (1971). Heterocyst formation and nitrogenase synthesis in Anabaena sp. A kinetic study. Archiv für Mikrobiologie 76, 139-150.

RippKa, R., Waterbury, J. \& Cohen-Bazire, G. (1974). A cyanobacterium which lacks thylakoids. Archives of Microbiology 100, 419-436.

RIPPKA, R. \& WATERBURY, J. B. (1977). Anaerobic nitrogenase synthesis in non-heterocystous cyanobacteria. FEMS Microbiology Letters 2, 8386. 
Simon, R. D. (1971). Cyanophycin granules from the blue-green alga Anabaena cylindrica: a reserve material consisting of copolymers of aspartic acid and arginine. Proceedings of the National Academy of Sciences of the United States of America 68, 265-267.

Simon, R. D. (1973). Measurement of the cyanophycin granule polypeptide contained in the bluegreen alga Anabaena cylindrica. Journal of Bacteriology 114, 1213-1216.

SмITH, A. J. (1973). Synthesis of metabolic intermediates. In The Biology of Blue-Green Algae, pp. 1-38. Edited by N. G. Carr and B. A. Whitton. Oxford: Blackwell Scientific Publications.

StANIER, R. Y. \& COHEN-BAZIRE, G. (1977). Phototrophic prokaryotes. The cyanobacteria. Annual Review of Microbiology 31, 225-274.

Stanier, R. Y., Doudoroff, M., Kunisawa, R. \& Contopoulou, R. (1959). The role of organic substrates in bacterial photosynthesis. Proceedings of the National Academy of Sciences of the United States of America 45, 1246-1260.
Stanier, R. Y., Kunisawa, R., Mandel, M. \& Cohen-Bazire, G. (1971). Purification and properties of unicellular blue-green algae (order Chroococcales). Bacteriological Reviews 35, 171205.

StewART, W. D. P. (1969). Biological and ecological aspects of nitrogen fixation by free-living microorganisms. Proceedings of the Royal Society B 172, 367-388.

Stewart, W. D. P., Haystead, A. \& Pearson, H.W. (1969). Nitrogenase activity in heterocysts of bluegreen algae. Nature, London 224, 226-228.

VAN Gorkom, H. J. \& Donze, M. (1971). Localisation of nitrogen fixation in Anabaena. Nature, London 234, 231-232.

Wilcox, M., Mrtchison, G. J. \& Smith, R. J. (1973). Pattern formation in the blue-green alga Anabaena. II. Controlled proheterocyst regression. Journal of Cell Science 13, 637-649. 